from going into collapse. In these cases, our treatment of them varies from two grains every ten minutes, to one grain every ten or twenty minutes, leaving directions that if the disease is not checked, the calomel is to be repeated oftener; we often, however, begin with two grains every ten minutes for three or four times, and then give it at wider intervals. The diarrhcea cases are all treated with a grain of calomel every one or two hours, for three or four times, with or without a few drops of laudanum, or cretaceous mixture.

And now, in bringing this paper to a conclusion, I must remark, that, rejoicing as $I$ do in the large opportunity my appointment has given me of testing once more my treatment; and fortunate as $I$ am in having such able and zealous coadjutors for my colleagues, who witness and rejoice in its success, I cannot forbear expressing $m y$ regret that the municipal authorities of this town, in 1832, refused compliance with my request, that a committee of six persons, three of whom should be medical, might be formed for visiting and reporting upon the state of all my cholera patients, and the results of the treatment. But especially I regret that an application has been declined which I made little more than a week ago, to the Board of Health, with a view to their sending down one or more medical inspectors to visit all our cases, and witness the treatment of them, and report weekly the results. Had this request been granted, I can believe that the question of its power to cure the disease would have been so settled in its fayour, and that a report of it going out first under the authority of government would have ensured its adoption wherever the disease prevailed.

A return made to the sanitary committee of the court of guardians for the poor of the town of Kingston-upon-Hull of the number of cases of diarrhoa and of cholera, incipient and entire, which came under the care of Dr. Ayre, physician, and Messrs. Day, H. Gibson, and Archbald, surgeons, between the 14th of July and the 6 th of August.

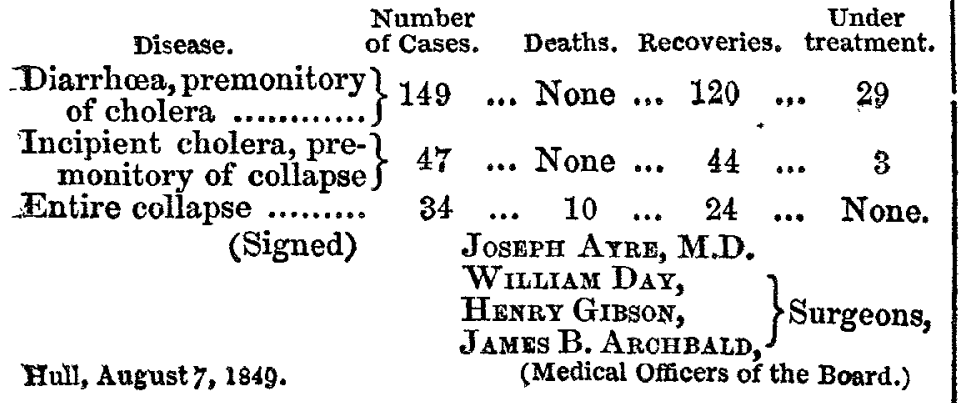

\section{SUCCESSFUL TREATMENT OF MALIGNANT CHOLERA ON THE PLAN OF DR. AYRE.}

BY GEORGE M. PRITCHETT, Esq., M.R.C.S., \&c., London.

As the medical world seems so much divided in opinion respecting the treatment of Asiatic cholera, and fully coinciding in the remarks made in last week's LANCET respecting the efficacy of the treatment adopted by Dr. Ayre of Hull, as evidenced in the diminished mortality in his practice, $I$ think it my duty to send for publication an outline of two well-marked cases successfully treated by his method. Several cases at an earlier stage have come under my notice, which have yielded like a charm to a very few grain doses of calomel and two drops of laudanum in four teaspoonfuls of brandy-andwater every hour only. In a disease of so much intensity, where we have so deadly a foe to grapple with, I think practice far better than theory, and it appears to me that we have at command a safe and simple treatment, almost specific, that were it generally adopted, would deprive the disease of nearly all its fell terrors. In Dr. Ayre's paper, published in TrE LAYCET of the 28th of October last, I find in 1832, that out of 219 cases there were 176 recoveries and only 43 deaths; while in this visitation the 59 cases, as appears in last week's LANCET, treated by him from the 14 th to the 26 th ult., were all successful, while nine treated by others all ended fatally. Surely such facts as these speak for themselves, and need no comment.

CASE 1.-D. A - a young barrister, aged twenty-five, who had been reading hard for some time, and also weakened considerably by previous indisposition, sent for me at three P.M. May 2nd. I found him before the fire on the sofa, complaining of much pain in the bowels, with a shrunken countenance of a dusky colour; frequent vomiting with diarrhoea, intermitting pulse, and slight cramps in the extremities. Thinking the attack would pass off by ordinary remedies, I prescribed a calomel-and-opium pill, and some simple effervescing draughts, with a few drops of laudanum in each dose, also brandy-andwater, \&c. At nine P.M. I was again called, when all the symptoms were much aggravated; diarrhca very frequent, stools, as well as could be ascertained, of the rice-water character; vomiting constant; rejection of all food and medicine as soon as taken; cramps violent all over the body and extremities; pulse very feeble and intermitting; the skin quite cold and livid; and the face had assumed that ghastly appearance so well known in this disease. No urine had passed since the commencement of the attack; and extreme collapse was rapidly supervening. The treatment adopted was simply a one-grain calomel pill every quarter of an hour, with two drops of laudanum in four teaspoonfuls only of brandy-and-water together with bottles of hot water applied to the extremities, and a mustard cataplasm to the pit of the stomach; in one hour the diarrhcea and vomiting ceased; in four, reaction had commenced, and the cramps were much lessened; twelve doses only were given in all. The after treatment was a little troublesome from the previously weakened state of the patient, but under simple remedies he rapidly progressed, and no prominent symptom need be enumerated.

CASE 2.-Mrs. S-, aged forty, living over stables in Chenies-mews, sent for me on the 11th of July, at seven A.M. I found she had had diarrhoea for some days previously, and had for some hours been getting gradually worse; in fact, all the symptoms of cholera were present, constant vomiting and purging, with well marked rice-water evacuations, quite unmixed with any freculent matter; urine suppressed; violent cramps; livid countenance; shrunk features; pulse scarcely to be felt; coldness of the surface, and collapse commencing. The treatment adopted was precisely the same as in Case 1 , with the same results. In one hour the vomiting and purging ceased; and in four the skin was getting warm; the calomel was continued at intervals of two and three hours during the day, the cramps not ceasing entirely.

July 12th.-Patient much better, only weak from the effects of the attack, with slight ptyalism of no importance. The patient progressed favourably under simple treatment, and in a fệ days was quite wẹll,

Store-street, Bedford-square, A ugtist, 18 490 .

\section{Betporir of A}

CASE OF ABSCESS OF THE SPERMA TIIC CORD.

\section{BY WILLIAM PHILPOT BROOKES, M.D., \&c.,}

SUROEON TO THE CHELTENHAM GENERAL HOSPITAL AND DISPENSARY, AND VISITING MEDICAL OPFICER TO THE CXELTENHAM COUNTY DIVISION OF LUNATIC ASYLUAS, \&c.

R. W-, aged fifty-one years, of active, spare habit of body, irritable and very anxious disposition, living as butler in the family of a gentleman in Cheltenham, enjoyed uninterrupted good health till within the last few months.

Six months back, after much pain and suffering, he passed a large-sized gravel-stone; after that time his usual good health was restored.

On Wednesday, June 28, 1848, I was requested to attend him. I found the patient suffering from fever, constipation, pain on pressure in the abdominal region, and extensive pain around the margin of the ribs of the right side. On examination of the groin I learnt that he had suffered for several years from a double inguinal hernia, and had constantly worn a truss of Salmon and Ody's construction. There was, on the right side, above Poupart's ligament, a round, cup-shaped depression, as large and deep as a small saucer, caused by the pad of the truss slipping out of its proper situation; and extensive pressure having been kept up with the pad, which was hard and convex on this spot, he complained of excruciating pain, and could barely allow it to be touched. The heat of the part was far above the natural temperature, and the skin was of a reddish-brown hue; the pulse was very quick and sharp; bowels had not acted for two days; tongue foul; hernia easily reduced. I ordered him five grains of calomel to be taken directly; a black draught in the morning; and a dozen leeches, with warm fomentations and poultices, to be applied to the abdomen afterwards. An enema to be given at bed-time if he had had no evacuation before that time.

June 29th.-Bowels not opened; the enema passed away without any frecal matter. Great pain over the whole abdomen and around the edges of the liver; tongue white and foul; pulse quick and wiry; urine scanty and high-coloured. To take two grains of calomel, and half a grain of opium, every four hours. An enema to be given directly; twelve leeches to be again applied over the bowels, and afterwards warm poultices to be kept constantly applied. 